\title{
Playing twenty questions with nature (the surprise version): reflections on the dynamics of experience
}

\author{
JOHN M. FLACH†, SIDNEY DEKKER $\$$ and PIETER JAN STAPPERS*§
}

$\dagger$ Department of Psychology, Wright State University, Dayton, OH, USA

† School of Aviation, Lund University, Sweden

$\S$ Faculty of Industrial Design Engineering, Delft University of Technology,

The Netherlands

It is a common complaint that the science of cognition does not do justice to either the reality of cognition in the wild or to the demands of engineering socio-technical systems. This article draws on examples from early functionalist/ pragmatist views in psychology, modern physics and dynamical systems theory to explore the ontological basis of this complaint. Tentative steps are made toward a new way to frame an ontology of experience. In this framework, the duality (complementary nature) of control and observation is offered as an alternative to the dichotomy (independent nature) of mind and matter.

\section{Keywords: WII}

\section{Introduction}

What must be admitted is that the definite images of traditional psychology form but the very smallest part of our minds as they actually live. The traditional psychology talks like one who should say a river consists of nothing but pailsful, spoonsful, quartpotsful, barrelsful and other moulded forms of water. Even were the pails and the pots all actually standing in the stream, still between them the free water would continue to flow. It is just this free water of consciousness that psychologists resolutely overlook. Every definite image in the mind is steeped and dyed in the free water that flows around it. With it goes the sense of its relations, near and remote, the dying echo of whence it came to us, the dawning sense of whither it is to lead. The significance, the value, of the image is all in this hallo or penumbra that surrounds and escorts it, or rather that is fused into one with it and has become bone of its bone and flesh of its flesh; leaving it, it is true, an image of the same thing it was before, but making it an image of that thing newly taken and freshly understood.

William James (1890, p. 255)

The failure of 'traditional psychology' to address the dynamics of experience noted by William James remains a serious problem, especially for those who hope to apply cognitive science to support operators who are trying to manage complex dynamic systems. The 'free water' that the cognitive scientists continue to resolutely overlook is typically the most interesting facet of cognition in the wild. The result is 
that there is a large gulf between 'cognitive science' and 'cognitive engineering'. Cognitive science tends to be organized around the buckets (laboratory microworlds) and the cognitive engineers are left to their own devices for addressing the free flow of behaviour in less controlled, natural environments. Cognitive engineers are painfully aware of this gap whenever they look to cognitive science for guidance. Cognitive scientists, however, seem to dismiss the gap, attributing it to the messiness and inferiority of 'applied' science.

Almost 100 years after James' warning, Allan Newell (1973) echoed a similar theme in his commentary on empirical research in cognitive psychology titled: 'You can't play Twenty Questions with nature and win'. The common theme is that the parsing of experience that guides research in cognitive science does not capture the 'flow' or 'dynamics' of experience in the wild outside the laboratory.

Despite repeated concerns expressed by people such as James and Newell, we wonder about the nature of the cognitive dynamic that invites scientists to develop 'snapshot' images of the process. Why do cognitive scientists continue to ignore the fluid aspects that are central to our experiences of the world? We wonder if this is not exclusively a problem for psychologists, but rather a general problem with how scientists and many other people view the world. The more general nature of this problem can be clearly seen in the tension between a 60 Newtonian (classical mechanics) view of nature and modern perspectives reflected in quantum mechanics. In the classical view of the world, space and time exist independently from an observer. This leads to a natural dichotomy between the world 'out there' and the experiences of that world 'inside' an observer's mind (e.g. the 'real' time on the clock and the 'experience' of time). However, modern physicists are beginning to consider the possibility that space and time are not out there, but rather they are intrinsic properties of experience. In some sense, the quantum reality emerges out of the experiencing of that reality. A different reality emerges (is created?) depending on the experimental questions addressed.

In the classical view, there is an objective world that exists independently from the

70 scientists/actors who might (or might not) occupy it. The world was there before these actors entered the stage and will continue to exist after the actors have passed on. While on the stage, the actors create a 'copy' of this world as 'knowledge'. They start with nothing, develop ideas (based on experience) and they test these ideas (through formal and informal experiments) to confirm how well the details of the copy match

75 the 'real' stage. The copy is often wrong and there are details that may never match the 'reality' due to limitations of perception and rationality.

In the modern view, the world is not a fixed stage independent of the actors who pass through it. The actors are participants whose actions contribute to the creation of the stage. The actors perform experiments and they get answers to the questions that they ask. They do their best to piece these answers into a coherent picture, because it is their preference to have a coherent picture. In fact, there is no true fixed stage (reality?), because the stage is continually being created and the models and questions that it stimulates are part of that creative process. In a real sense, the actors are having a conversation with nature and what nature 'says next' depends

85 on what the actors 'ask'. In the modern view, the dynamic conversation is the reality and the fixed poles of independent actor and world are fictions (attributes of the mental models not truths based in an independent reality as posited in the classical view). 
This dynamic in which reality emerges as a consequence of our experience is nicely illustrated in an alternative version of the Twenty Questions game described by the physicist John A. Wheeler (1980):

You recall how it goes - one of the after-dinner party sent out of the living room, the others agreeing on a word, the one fated to be questioner returning and starting his questions. 'Is it a living object?' 'No'. 'Is it here on earth?' 'Yes'. So the questions go from respondent to respondent around the room until at length the word emerges: victory if in twenty tries or less, otherwise, defeat.

Then comes the moment when we are fourth to be sent from the room. We are locked out unbelievably long. On finally being readmitted, we find a smile on everyone's face, sign of a joke or a plot. We innocently start our questions. At first the answers come quickly. Then each question begins to take longer in the answering - strange when the answer itself is only a simple 'Yes' or 'No'. At length, feeling hot on the trail, we ask, 'Is the word 'cloud'?' 'Yes', comes the reply, and everyone bursts out laughing. When we were out of the room, they explain, they had agreed not to agree in advance on any word at all. Each one around the circle could respond 'yes' or 'no' as he pleased to whatever question we put to him. But however he replied he had to have a word in mind compatible with his own reply - and with all the replies that went before. No wonder some of those decisions between 'yes' and 'no' proved so hard!

In the real world of quantum physics, no elementary phenomenon is a phenomenon until it is an observed phenomenon. In the surprise version of the game no word is a word until that word is promoted to reality by the choice of questions asked and answers given. 'Cloud' sitting there waiting to be found as we entered the room? Pure delusion!

(pp. 392-398)

Perhaps all cognitive systems, not just the quantum physicists, are playing the 'surprise' version of the Twenty Questions game described by Wheeler. That is, 115 nature unfolds one step (question) at a time. Nature is not sitting out there waiting for us to discover and 'copy' or 'map' it. Nature does not exist 'out there' waiting to be surveyed. Rather nature itself is unfolding one step at a time as a consequence of our actions. The dynamic of experience is generated as a result of the actions of the cognitive system. Adaptation is not a one-way, simple causal affair with the cognitive

120 system adapting to a fixed environment. Rather, adaptation implies a circular dynamic where 'fitness' emerges as a result of mutual, ongoing changes in both the cognitive system and its environment. As Weick (1995) suggests:

... there is not some kind of monolithic, singular, fixed environment that exists detached from and external to these people. Instead, in each case the people are very much a part of their own environments. They act, and in doing so create the materials that become the constraints and opportunities they face.

In the same vein, Hutchins (1995) observed in describing the relationships between navigators and their artefacts/tools (e.g. maps and instruments) that 'humans create their cognitive powers by creating the environments in which they exercise those powers' (p. 169). Juarrero (1999) makes a similar point in the context of the dynamics of action. She writes:

... complex adaptive systems are typically characterized by ... feedback processes in which the product of the process is necessary for the process itself. Contrary to Aristotle, this circular type of causality is a form of self-cause... when parts interact to produce wholes, and the resulting distributed wholes in turn affect the behavior of their parts, 
interlevel causality is at work. Interactions among certain dynamical processes can create a systems-level organization with new properties that are not the simple sum of the components that constitute the higher level. In turn, the overall dynamics of the emergent distributed system not only determine which parts will be allowed into the system: the global dynamics also regulate and constrain the behavior of lower-level components. The theory of complex adaptive systems can therefore be used for this form of causal relations, which had puzzled Kant as a form of causality 'unknown to us'.

For some ranges of phenomena, for example, the sphere where classical mechanics leads to valid predictions, the impact of the actor/observer on the dynamic conversation may be so small that it can be ignored. But in other ranges, for example, at the quantum scale, the observer/actor's contributions are large enough to have a significant impact on the phenomena. We are suggesting that cognitive phenomena such as learning, memory, decision-making and problemsolving are more similar to quantum scale phenomena than to classical mechanics. For cognitive phenomena, the impact of the actor/observer on the dynamic is a significant part of the story. For this reason, the relational interactions reflected in field constructs may be more central to the dynamic of cognition than the separate elements (e.g. mind and matter) suggested by intuitions grounded in classical mechanics.

This position is consistent with James' philosophy of radical empiricism. Nature does not stand outside the dynamic of interaction. Nature is generated (created) by the actions of cognitive systems. In this view, mind and matter disappear as objects of interest - the scientist is challenged to focus on the 'field' of experience, the field of adaptation as the object of study. Gibson and Crooks' (1938) hypothesis about the safe field of travel in relation to driving automobiles was one of the first papers to suggest such a field analysis. They describe the field of safe travel as follows:

The field of safe travel... is a spatial field but it is not fixed in physical space. The car is moving and the field moves with the car through space. Its point of reference is not the 165 stationary objects of the environment, but the driver himself. It is not, however, merely a subjective experience of the driver. It exists objectively as the actual field within which the car can safely operate, whether or not the driver is aware of it. It shifts and changes continually, bending and twisting with the road, and also elongating and contracting, widening or narrowing, according as obstacles encroach upon it and limit its 170 boundaries.

It is interesting to note that the concept of 'field' itself is a conceptual model that physics has developed to keep track of the relationships that happen over space and time. For example, consider the comments of Wheeler (1998):

It is to Aristotle, working in the fourth century B.C., that we owe the popular maxim that 'nature abhors a vacuum'. It is more accurate to say that people abhor a vacuum. Newton called it an absurdity. Scientists ever since have developed our picture of nature in terms of what I may call 'local action', to distinguish it from 'action at a distance'. The idea of local action rests on the existence of 'fields' that transmit action from one place to another. The Sun, for instance, can be said to create a gravitational field, which spreads outward through space, its intensity diminishing as the inverse square of the distance from the Sun. Earth 'feels' this gravitational field locally - right where Earth is - and reacts to it by accelerating toward the Sun. The Sun, according to this description, sends its attractive message to Earth via a field rather than reaching out to influence Earth at a distance through empty space. Earth doesn't have to 'know' that there is a sun out there, 93 million 
miles distant. It only 'knows' that there is a gravitational field at its own location. The field, although nearly as ethereal as the ether itself, can be said to have physical reality. It occupies space. It contains energy. Its presence eliminates a true vacuum. We must then be content to define the vacuum of everyday discourse as a region free of matter, but not free of field.

As Wheeler implies, it is the human model of reality that precludes 'action at a distance' and requires constructs such as 'ether' and 'field' to keep track of interactions that happen over space. The importance of the field concept for bringing time into a unified picture with matter and space is reflected in Feynman et al.'s (1963) comments on the field construct:

It [the field construct] would be trivial, just another way of writing the same thing, if the laws of force were simple, but the laws of force are so complicated that it turns out that fields have a reality that is almost independent of the objects which create them. One can

200 do something like shake a charge and produce an effect, a field, at a distance; if one then stops moving the charge, the field keeps track of all the past, because the interaction between two particles is not instantaneous. It is desirable to have some way to remember what happened previously. If the force upon some charge depends upon where another charge was yesterday, which it does, then we need machinery to keep track of what went on yesterday, and that is the character of a field. So when the forces get more complicated, the field becomes more and more real, and this technique becomes less and less of an artificial separation.

(pp. 12-18)

We believe that the perspectives offered by the 'surprise' version of Twenty

210 Questions and constructs such as 'field' force us to reconsider the dynamics of cognitive systems - and to re-evaluate constructs associated with memory, rationality and decision-making in ways that were suggested by pragmatists such as Peirce, James and Holmes at the turn of the century (e.g. Menand 1997, 2001). We cannot look to a natural world or to a logical rationality that stands apart from the 215 dynamic flow as a ruler against which to measure the dynamic. Instead, we must look to the dynamic itself to discover intrinsic properties from which to bootstrap our science. Holmes clearly articulates the implications of this dynamic for common law:

The life of the law has not been logic; it has been experience... In order to know what it is, we must know what it has been, and what it tends to become. We must alternately consult history and existing theories of legislation. But the most difficult labor will be to understand the combination of the two into new products at every stage.

[Cited from Menand 1997, p. 137; emphasis added]

Hints about the nature of this dynamic in which experience emerges as a product of where we are and where we are going can be seen in the 'hindsight' bias that was first described by Fischoff $(1975,1982)$. This phenomenon nicely illustrates the 'dynamic' (i.e. the time dependent) nature of cognition. This phenomenon might be a good place to begin our struggle to frame a cognitive science that considers the free flow of life ignored by the buckets of classical cognitive paradigms. We begin by 230 considering hindsight, then move on to consider human error, learning and memory. Then we postulate a general framework for visualizing cognition in the context of a modern view in which the reality of cognition is viewed as a dynamical coupling of mind and matter. 


\section{The hindsight bias}

Judges possessing outcome knowledge may, for example, tend to reverse their temporal perspective and produce scenarios that proceed backward in time, from the outcome to the preceding situation. Such scenario retrodiction may effectively obscure the ways in which events might have taken place, much as solving a maze backward can obscure the ways in which one might have gotten lost entering from the beginning.

(Fischoff 1975, p. 298).

Fischoff (1975) reported a series of experiments that demonstrated how knowledge of outcome increases the postdicted likelihood of outcomes and changes the perceived relevance of event-descriptive data. For example, after an event has happened (e.g. the destruction of the World Trade Centre), people revise the estimate of the prior probability of the event to be more in line with that outcome ('the American intelligence community should have seen this coming'). Even when they are asked to recall actual estimates that they had made prior to an event - their memories of the previous estimates are 'biased' to be more in line with the known 250 outcomes (after 9-11, some people report that the prior 'signs' were obvious to them). The term 'bias' in this case implies an error in that the estimates at recall do not match estimates that were recorded prior to knowledge of the outcome. In other words, people consistently overestimate what they or others thought or could have known prior to knowledge of an outcome.

Virtually all reports of the hindsight bias, whether experimental (e.g. Fischoff 1975, Carroll 1978, Hawkins and Hastie 1990, Koehler 1991) or historical (e.g. Roese and Olson 1996), focus on the ex post facto distortions brought on by knowledge of outcome, relative to uncontaminated ex ante judgements about the same outcome or events. The delta between these two is what makes the hindsight bias a bias:

260 a deviation between judgements made after the outcome and 'objective' measures made prior to knowledge of the event. There is an implication here that the estimates made prior to an outcome are 'objective' standards against which later judgements can be measured. That is, the prior estimates have a 'privileged' status relative to estimates made after the event. Again, the hindsight estimates are considered the 'errors'.

The 'bias' or 'error' perspective leads Fischoff (1975) to conclude that because of the hindsight bias, 'the very outcome knowledge which gives us the feeling that we understand what the past was all about may prevent us from learning anything from it' (p. 299). He and others have suggested that this bias might lead to a 'creeping 270 determinism in which people see the world as more predictable than it 'truly' is. As Weick (1995, p. 28) puts it: 'people who know the outcome of a complex prior history of tangled, indeterminate events remember that history as being much more determinant, leading'inevitably' to the outcome they already knew'. Reason (1990) also reminds us how hindsight changes past indeterminacy and complexity into order, structure and oversimplified causality.

In essence, Fischoff, Weick and Reason are suggesting that the hindsight bias leads to an illusion of a linear, causal world; when, in fact, we live in a chaotic, uncertain world. There is the implication that one of these descriptions is 'true' with regard to the way the world 'really is' and the other description is a 'false' 280 impression, reflecting limitations of our internal information-processing mechanisms. It is tempting to compare the causal illusion with a Newtonian view of nature and the chaotic reality with a quantum view of nature. The quantum view 
suggests that it may be the 'story' or 'model' that demands a coherent thread, not nature.

Perhaps it is a mistake to think of the pre-post responses in the hindsight paradigm as either 'objective truth' or 'error'. Rather, the different responses reflect the dynamics of cognition, where reality unfolds over time. The changes are simply evidence of the integrative, flowing nature of this reality.

\section{Human error?}

In situations where information is limited and indeterminate, occasional surprises - and resulting failures - are inevitable. It is both unfair and self-defeating to castigate decision makers who have erred in fallible systems, without admitting to that fallibility and doing something to improve the system.

(Fischoff 1975, p. 298)

As the quote from Fischoff suggests, the tendency to oversimplify the complexity of nature has obvious implications for the study of the role of human 'errors' in accidents. Woods et al. (1991) have also commented on the impact of hindsight bias on accident investigations:

300 Given knowledge of outcome, reviewers will tend to simplify the problem-solving situation that was actually faced by the practitioner. The dilemmas, the uncertainties, the tradeoffs, the attentional demands, and double binds faced by practitioners may be missed or underemphasized when an incident is viewed in hindsight... Possessing knowledge of the outcome, because of the hindsight bias, trivializes the situation confronting the practitioners and makes the correct choice seem crystal clear.

(pp. 7-8)

Perrow (1984) suggests that other factors, in addition to hindsight bias, may help to put the operator squarely in the cross-hairs of any investigation:

Formal accident investigations usually start with an assumption that the operator must have failed, and if this attribution can be made, that is the end of serious inquiry. Finding that faulty designs were responsible would entail enormous shutdown and retrofitting costs; finding that management was responsible would threaten those in charge, but finding that operators were responsible preserves the system, with some soporific injunctions about better training.

However, it is not just the people conducting the formal accident investigations who may fall prey to the hindsight bias. The operators, themselves, can also find that it is impossible to turn back time, to 'see' the world as it looked prior to an accident. For example, Snook (2000) investigated how, in the fog of post-Gulf war Iraq, two 320 helicopters carrying UN peacekeepers were shot down by American fighter jets. The situation in which the shoot-down occurred was full of risk, role ambiguity, operational complexity, resource pressure, slippage between plans and practice. Yet immediately after the incident, all of this gets converted into binary simplicity (a choice to err or not to err) by DUKE - the very command onboard the airborne control centre whose job it was not to have such things happen. Allowing the fighters to shoot down the helicopters was their 'error', they tend to believe that they should have been able to 'see' and prevent the disaster. It was said of the DUKE that 
immediately after the incident: 'he hoped we had not shot down our own helicopters and that he couldn't believe anybody could make that dumb of a mistake' (Snook 2000, p. 205).

It is DUKE himself who blames his own dumb mistake. As with the 'errors' in the previous chapter, the dumb mistake is something that jumps into view only with knowledge of outcome, its 'mistakenness' a function of the outcome, its 'dumbness' a function of the severity of the consequences. While doing the work, helping guide the fighters, identifying the targets, all DUKE was doing was his job. Normal work. He was not sitting there making 'dumb mistakes'. They are a product of hindsight, his own hindsight, directed at his own 'mistakes'.

The fighter pilots in this friendly fire incident also engaged in self-blame, literally converting the ambiguity, risk, uncertainty and pressure of their encounter with potentially hostile helicopters into a linear series of decision errors, where they repeatedly and consistently took wrong turns on their road to perdition (we (1) misidentified; (2) engaged; (3) destroyed): 'Human error did occur. We misidentified the helicopters; we engaged them; and we destroyed them. It was a tragic and fatal mistake'. Tiger 02 quoted in Snook (2000, p. 205).

This self-blame seems to be inconsistent with attribution theory. Jones and Nisbett (1971) documented the tendency of actors to attribute their actions to external situational causes, whereas observers (by contrast) attribute the same actions to causes internal to the actor(s). They called this tendency the 'actorobserver divergence'. A few years later, the 'fundamental attribution error' described 350 how observers underestimate the impact of situational forces and overestimate the importance of internal dispositional factors (Ross 1977).

The fundamental attribution error makes the wrong prediction with regard to DUKE and the fighter pilots. If it were true, then these 'actors' would tend to blame context for their own 'errors'. Indeed, it was a rich enough context - fuzzy,

355 foggy, dangerous, multi-player, pressurized, risky - with plenty of 'blameworthy' factors to go around. If that is where you would look. Yet these actors do not. $W e$ misidentified, we engaged, we destroyed. The pilots had the choice not to; in fact they had a series of three choices not to instigate a tragedy. But they did. Human error did occur. Of course, elements of self-identity and control are wrapped up in such an attribution, a self-identity for which fighter pilots may well be poster children.

On the other hand, attribution theory may make the right prediction with regard to the behaviour of accident investigators, who can have a strong tendency to focus on the personal shortcomings of others (e.g. crewmembers 'lose situation awareness', 365 or display 'ineffective crew resource management'). Human factors professionals often justify their involvement in design of safety critical systems with the claim that a large percentage of accidents are due to 'human error'. This approach to self-promotion may help to institutionalize the fundamental attribution error. Such deep-seated reflexes prompt Snook (2000) to comment that the fundamental attribution error is alive and well.

As Rasmussen (1986) and others have repeatedly observed, it is likely that there will be a human action or failure to act along any path to catastrophe. Thus, it is tempting for investigators to 'blame' the human as the cause of the catastrophe. However, stamping out human errors does not necessarily lead to safer systems 375 (any more than stamping out forest fires leads to safer forests). The forest service has learned that a safety programme that focuses only on stamping out fires may actually 
contribute to catastrophic forest fires - because this leads to the accumulation of fuel on the floors of forests and eventually results in fires that burn at an intensity that is catastrophic to the forest.

380 The forest service is beginning to learn that managing forests requires more than stamping out fires and that small fires can be essential to the natural evolution and health of a forest. Perhaps it is time to consider the possibility that human error is essential to the larger dynamic of human growth and development. As Rasmussen (1986) noted: 'human variability is an important ingredient in adaptation and

385 learning, and the ability to adapt to peculiarities in system performance and optimize interaction is the very reason for having people in a system. To optimize performance, to develop smooth and efficient skills, it is very important to have opportunities to 'cut corners', to perform trial and error experiments...' (p. 150). A safety programme that fixates on stamping out human error may lead to a brittle system where catastrophic failures are actually more likely, because people are not able to get the full range of experience necessary for skill development and expertise.

\section{Beyond error: learning from our mistakes}

Knowledge and error flow from the same mental sources, only success can tell the one from the other.

(Mach 1905, p. 84)

This quote from Ernst Mach reflects a new look at human error (e.g. Rasmussen 1986, Reason 1990, Rasmussen and Svedung 2000). Again, as Rasmussen (1986, p. 150) wrote: 'human variability is an important ingredient in adaptation and learning... and in a way human errors can be considered unsuccessful experiments with unacceptable consequences'. Similarly, Reason (1990, p. 1) wrote that: 'far from being rooted in irrational or maladaptive tendencies, these recurrent error forms have their origin in fundamentally useful psychological processes'.

It is tempting to speculate that the failure of attribution theory with regard to the 405 behaviour of those involved in the friendly fire incident reflects this adaptive nature of human cognition. Where Fischoff (1975) sees the hindsight bias as an obstacle that might interfere with our ability to learn from the past, we wonder whether just the opposite is true. Perhaps the hindsight 'bias' helps to ensure that we do learn from our errors. Consider this quote from Dominguez's (1995) analysis of the conversion 410 decision in the context of laparoscopic cholecysectomy:

I would be trying to shoot an intraoperative cholangiogram before I'd go ahead and clip that but then again that's just my own bias from my own previous experience from having a ductile injury. In that girl, [she] had a fairly acute disease, wasn't quite as bad looking as this but everything was fine until 5 days post-op when she came back to the office just still puking her guts out. And I'd just destroyed her hepatic duct, her common hepatic duct, because I hadn't realized where we were and that was an error on my part and I had been fooled by the size of her cystic duct. The stone, it had been a good size stone, it had worked its way down chronically to the cystic duct enlarging it so that it looked like the infundibulum of the gallbladder and then at the common duct junction I thought the common duct was the cystic duct so I went ahead and clipped it, divided and then started cauterizing. Well when you cauterize up through there you've got the hepatic duct line right behind it and I eventually burned that part. If you talk to any other surgeons who've 
had that kind of an injury, I mean I lost sleep for several nights over that. It's one of those things that haunt you and you hate it, you just hate it.

Perhaps the error was an inevitable result of the uncertainties associated with surgery. And perhaps this surgeon is castigating himself too severely, given the inevitability of errors in this type of environment. However, we suspect that this surgeon will move into the future with a greater awareness of the potential for danger and that he will be a much better (safer) surgeon as a consequence. In this sense, the adaptation process may involve a migration toward the boundaries of safety. The consequence of crossing a boundary (an error) may be an over-correction in favour of caution (in this sense it is a bias - incorrectly feeling that I should have seen the error coming). While clearly not optimal in a normative statistical sense grounded in some 'objective' past, this may lead to a system that satisfies in favour of safety! Such a system, one who 'errs' in the direction of caution, may well be more likely to survive in an uncertain world than one who optimizes around a perfect memory of a particular history (that might reflect both real and coincidental patterns). The belief that he should or even could have seen the error coming may not be an objective assessment of the past event. However, it may be an assessment that ensures that he will see it coming in the future! In essence, we are suggesting that the 'subjective' experience of the surgeon may provide a better map for the future than any supposedly 'objective' reconstruction of the past.

Thus, the challenge of managing safety critical systems may depend on the learning experiences of the humans managing the system. And making mistakes may

445 be a key dimension of that experience - particularly for complex work environments. Perhaps the growth of skill depends, in part, on the opportunity to make lots of errors, and perhaps a key aspect of managing safety is to provide forgiving environments, where these necessary errors do not lead to catastrophic consequences. For example, this is likely to be one of the values of simulators - they offer an opportunity to learn from mistakes in a forgiving environment. In addition, the inclusion of 'near miss' reports in safety reporting systems provides an important opportunity to learn from these small 'fires' (errors) in ways that may help to ensure the long-term health of the 'forest' (system).

\section{Beyond memory: predicting the future}

... the theory of information pickup does not need memory. It does not have to have as a basic postulate the effect of past experience on present experience by way of memory. It needs to explain learning, that is, the improvement of perceiving with practice and the education of attention, but not by an appeal to the catch-all of past experience or to the 460 muddle of memory.

The state of a perceptual system is altered when it is attuned to information of a certain sort. The system has become sensitized. Differences are noticed that were previously not noticed. Features become distinctive that were formerly vague. But this altered state need not be thought of as depending on memory, an image, an engram or a trace. An image of the

465 past, if experienced at all, would be only an incidental symptom of the altered state.

(Gibson 1979, p. 254)

It's a poor memory that only works backwards.

(White Queen to Alice; Lewis Carroll 1954) 
Fischoff's (1975) fear that hindsight bias will interfere with our ability to learn from the past is a natural conclusion if one treats 'learning' as being analogous to the 'storage' of information in memory. This view stems back to the early work of Ebbinghaus and others who scored learning relative to a participant's ability to accurately recall nonsense syllables that had been presented on a past list. In these laboratory paradigms the lists constitute an absolute archive of the past and learning meant accurately reproducing that 'past' list. However, we wonder whether this is representative of the dynamic of learning in the wild. In the wild, is learning scored against the past or against the future?

Consider Loftus's (1975) work on 'eyewitness testimony' and the 'misinformation' effect. In one version of this paradigm, participants see a video of an accident event involving a stop sign. In some conditions, later interviews about the accident include misinformation, suggesting that the sign was a different type (yield). Results show that some of the subjects who were presented with the 'misinformation' erroneously report 'seeing' the yield sign during the original event. As in the Ebbinghaus' experiments, the videotape is an absolute archive of the past against 485 which memory is scored. It seems that some of the participants integrated the misinformation with the initial event and thus committed an error.

Does Loftus's work reveal a limitation of memory, or does this work reveal a generally adaptive pattern of learning in which judgements about the world are made based on an integration of experience over time? Perhaps the memory 'error' is not

490 a weakness of memory, but rather reflects a particularly 'unkind' context that Loftus has created. If one allows that every particular perception of the world (the original video tape and the later interview containing the misinformation) contains both signal and noise with regard to anticipating the future, then generalizing from ideal observer theory it might be expected that an integrative process might provide more accurate predictions than a storage process. An integral process can be tuned to 'filter' noise or conversely to 'amplify' the signal (see chapter 18, Jagacinski and Flach 2003, which describes the design of a simple observer). In other words, the integral process can reconstruct a stable pattern from noisy observations that are sampled over time; and it can do this without storing (or remembering) past samples!

500 It does this by considering the momentary expectation relative to the current sample and then revising the expectation according to the degree of mismatch (error or surprise). The revised expectation is an integration of all previous errors, but neither the errors nor the samples are stored - the expectation is the only 'trace' of the past experiences. If the noise is random, then over the long run, this approach

505 should converge to expectations that are consistent with the signals. Certainly, this was not true in the experimental context created by Loftus. However, the important question is whether it is true with regard to experiences in the wild. Unlike in the experimental context we are trapped in our own experience. That is, we generally do not have a video-tape recording as an 'objective' standard against which our 'subjective' impressions can be scored.

The high school football coach is an interesting case. During the season, he experiences a critical event every Friday night and then spends the week trying to learn from this experience so that he can be prepared for the next critical event. In this case there often are video-taped records to assist the reconstruction of the 515 past. Suppose we ask him to record his impressions during or after the game on Friday night. During the next week he will spend hours reviewing films of the game and talking to his assistant coaches and players about their impressions. 
Suppose we ask him to recall his original impressions made during the game at the end of the week. Do you suppose his 'memory' might be 'biased' by the events of the intervening week? To what extent do you think success in the next game depends on accurate recall of his original impressions? Which impressions do you think will be more useful for guiding his choices in the next game - his original impressions or the impressions that have been formed after a week of discussion and analysis? Do you know of any coaches who lost their jobs because they failed a test requiring precise recall of events in a previous game? In the wild, recall of the last game may not be so important as winning the next game.

We suggest that the case of the football coach is more representative of the natural dynamic of cognition than the verbal learning tasks that provide the empirical foundation for theories of memory. We wonder how often survival depends on the ability to accurately repeat lists of nonsense syllables presented at some specific time in the past. On the other hand, it is not so easy to find studies of how people learn to perform a complex task, such as coaching a winning football team, or even to find studies about how more common skills, such as driving a car, are learned. We find it quite interesting that in almost all texts on cognition (e.g. Medin and Ross 1992) 'learning' and 'memory' are covered in separate chapters with essentially no common citations. This suggests to us that even the cognitive scientists recognize that theories of 'memory' are irrelevant to the problem of 'learning'. It is also interesting that most of the empirical base in the chapters on learning come from animal studies. Could it be that the 'memory' and 'learning' described in these texts has more to do with the buckets of cognitive science than with the natural dynamic of learning and adaptation in the wild?

The idea of adaptation as integration over time rather than storage of data is more consistent with Bartlett's observations of remembering. Bartlett found that recall of stories showed systematic distortions over time that reflected the cultural context of the participants in his studies. This is consistent with the idea that over time the story event was integrated with other common experiences. Like Loftus, Bartlett also created a particularly 'unkind' environment for his participants, choosing stories from foreign cultures that did not easily fit into his participants' cultural context. From the point of view of traditional theories, the distortions in recall reflect 'errors' of memory. However, we wonder if these distortions do not simply reflect the natural dynamic of 'sensemaking', as described by Weick (1995). As Weick (1995) noted, important features of the dynamic of sensemaking is that it is 'retrospective', 'ongoing' and 'enactive'.

The integrative aspects of 'remembering' in a work context were illustrated beautifully by Hutchins (1995) in the context of his analysis of ship navigation:

I began this section with the question of what it might mean that a watchstander can 'remember the elements of a procedure'. The answer is clearly not that something is retrieved from memory as a physical structure might be retrieved from a storehouse, or even as a pattern of bits might be retrieved from a magnetic storage medium in a

560 computer. Rather, remembering is a constructive act of establishing coordination among a set of media that have the functional properties such that the states of some can constrain the states of others, or that the state of one at time $t$ can constrain its own state at $t+1 \ldots$ Remembering is not a retrieval of an identifiable single structure; rather, it is a process of construction via simultaneous superimposition of many kinds of 565 constraints. 
Hutchins (1995) goes on to consider the implications of this image of remembering for our image of learning:

The process by which an individual learns to perform the task can be seen as the propagation of a wave of organization moving across a complex of media. Organization propagates from external media to internal media and back to external media. The changes that happen inside an individual as a consequence of learning are adaptations in a part of a larger dynamical system to organize or structure that is present in other parts of the system.

(p. 310)

\section{Living over time rather than in time}

The components and events of the environment fall into natural units. These units are nested. They should not be confused with the metric units of space and time.

(Gibson 1979, p. 15)

The flavour of the sensemaking dynamic is captured by the phrase: 'how can I know what I think until I see what I say' Weick (p. 61, 1995; original source of quote is E.M. Forster 1972). Classically, cognitive psychology has employed time as an absolute ruler for parsing events into 'stimuli' and 'responses' or into 'causes' and 'effects'. This assumes an objective basis for distinguishing the past, present and future - and assumes that the cognitive experience can be parsed into a sequence of distinct instances, one clearly before or after the other; with the prior events 'causing' the later events. Thus, the causal question comes down to the simple question of which came first: 'what I think' or 'what I say'. However, if you consider 'thinking' and 'saying' as events that happen over time and you consider the possibility that one might 'feed back' to effect the other, then there is, in fact, no logical priority in time. And, thus, no clear criterion for identifying which is the cause of the other. 'What I am thinking' may constrain or shape 'what I am saying' while at the same time 'what I am saying' is shaping 'what I am thinking'.

This problem is often discussed in the context of goal-directed behaviour and the concept of 'teleology'. As Miller et al. (1960) point out, prior to the introduction of the cybernetic hypothesis 'psychologists generally regarded 'teleological' and 'unscientific' as synonymous and it was therefore surprising to realize that machines could strive toward goals, could collect information about the difference between their intentions and their performance and then work to reduce that difference' (p. 42). The 'goal' or 'end' is in the future, so how can it have a causal role in organizing behaviour? One solution is to introduce an 'intention' or a 'plan' as a prior cause of the behaviour. However, even in the simplest servomechanism the reference signal (which would be the analogue to an intention) is not an

605 instantaneous event. The reference exists over time. As behaviour unfolds, the consequences at each point in time are compared to this reference in order to generate the 'error' signal. In the simple servomechanism, the reference exists over time, and the error signal is both the 'driver' of behaviour and the consequent of behaviour. Again, the circular nature of the control dynamic does not map easily onto classical notions in which causes are temporally prior to effects. In the classical 
sense, neither reference, error nor behaviour maps easily onto the concepts of either cause or effect. Each constrains the others, but neither determines the others.

The challenge, as reflected in the quote from Gibson that introduced this section, is to discover the natural units for parsing cognitive activity into a nested set of units that preserve the 'meaningful' threads that extend across time.

\section{Intentional dynamics}

This view of space as a dynamic entity - every part of which is influenced by, and influences, every other part - is quite different from Newton's conception of the ether. His ether was a passive background, more like the canvas of a painting hung in a museum than the canvas of a circus tent rippling in the wind.

(Wheeler 1998, p. 326)

Reasoning like this has made me ask whether the universe is a 'self-exciting circuit' a system whose existence and whose history are determined by measurements. By 'measurement' I do not mean an observation carried out by a human or a humandesigned instrument - or by any extraterrestrial intelligence, or even by an ant or an amoeba. Life is not a necessary part of this equation. A measurement, in this context, is an irreversible act in which uncertainty collapses to certainty. It is the link between the quantum and the classical worlds, the point where what might happen - multiple paths, interference patterns, spreading clouds of probability - is replaced by what does happen: some event in the classical world, whether the click of a counter, the activation of an optic nerve in someone's eye, or just the coalescence of a glob of matter triggered by a quantum event.

(Wheeler 1998, p. 338)

The simple servomechanism provides a good example of how perception and action can be coupled in a circular causality. However, it fails to capture important aspects of cognition associated with the origin and evolution of intentions. With the servomechanism, the reference signal is defined from outside the dynamic (it is the 'input' to the system). One approach to capturing the intentional dynamics is to

640 add 'outer' loops as the source of references for inner loops. For example, Powers $(1973,1998)$ argues for a hierarchical nesting of control loops, where outer loops (or higher levels) provide the references for inner loops (or lower levels). However, a danger of this approach is getting caught in an infinite regression, as more and more loops have to be added.

645 Others have also recognized the closed-loop coupling of perception and action, most notably Neisser's (1976) perceptual cycle. The perceptual cycle has figured prominently in discussions of situation awareness (Adams et al. 1995, Smith and Hancock 1995), but overall the impact of Neisser's important critique of cognitive psychology has been disappointing. We hope to amplify Neisser's message by adding

650 a twist to his perceptual cycle, as illustrated in figure 1. Perhaps this alternative representation will be more consistent with Wheeler's description of a 'dynamic entity', where 'every part of which is influenced by, and influences every other part'. A dynamic where what 'might happen' collapses into what 'does happen;' where possibilities collapse into actions; actions collapse into consequences; consequences collapse into beliefs; and beliefs collapse into new possibilities. 


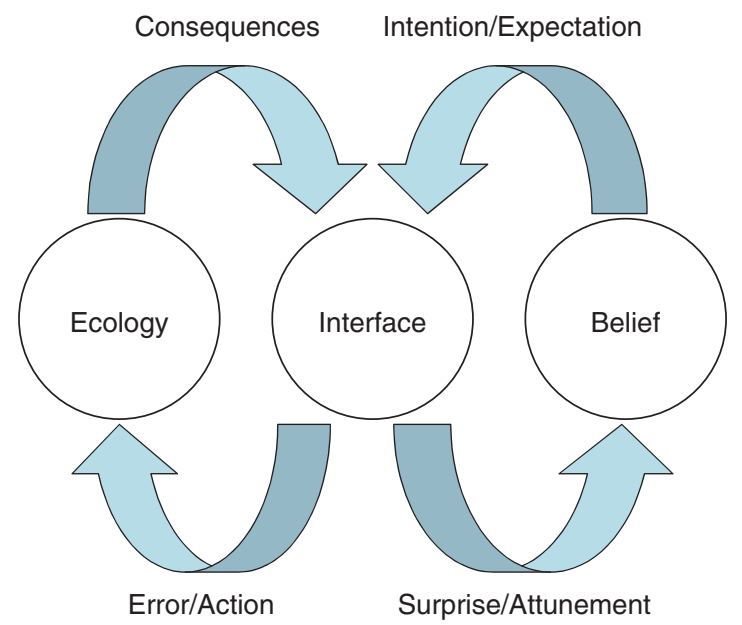

Figure 1. An image of the dynamics of cognition, where control processes are intimately linked with abductive processes in an intimate dance, where exploratory and performatory actions collaborate in an evolution that typically moves toward higher degrees of 'fitness' or 'stability'.

The circles in figure 1 represent three conceptual 'images' of constraint that participate in the dynamic. The arrows reflect salient aspects of the coupling among the three sources. The sources of constraint are coupled in a dance in which each is changing and being changed by the others. One source of constraint is the ecology. The label 'ecology' is carefully chosen in opposition to the more conventional term 'environment'. First, the ecology is part of the system of interest. It is not outside the system as implied by the term 'environment'. Second, the ecology is defined relative to an organism. Consistent with Gibson's (1979) construct of 'affordance', the ecology reflects the possibilities for action. These possibilities arise from the 665 reciprocal relationships between an organism (with a certain size and specific effectors) and other animate and inanimate objects. Whereas, Gibson focused on the physical environment relative to perception/action, we prefer to use the term more broadly to include the social, organizational and cultural constraints in addition to physical constraints on action. We believe that social conventions (e.g. gender roles) can be as strong a force in shaping the dynamic of cognition as physical forces (e.g. the laws of inertia).

Thus, the ecology reflects the opportunities for action and the associated consequences of action (including inaction as the null case of action). In the context of Hutchins' analysis of ship navigation, the ecology would reflect the harbour with 675 its landmarks, traffic, etc. through which the ship is sailing. The properties of this harbour would be described relative to the ship. For example, a passable channel for one type of ship might not be passable for another. The ecology is not a stage independent of an actor - it is simply one way of talking about the relationship between stage, actor and play. The ecology is not outside the 'system'. It is one facet of the dynamic coupling of mind and matter.

The focus on possibilities for action in the ecology is consistent with the important insights that information theory offers (Shannon and Weaver 1949). To understand the significance of an action, choice or event, it is important to know 
not simply the event, but also the set of possibilities from which that event was drawn. Understanding the space of possibilities is critical for understanding the dynamics of cognition. This is also reflected in Simon's (1981) analogy of the ant on the beach. To understand problem-solving, it is important to have a clear understanding of the 'problem space' or 'task environment' (Newell and Simon 1972). Again, this reflects the space of possibilities, not simply a specific activity path.

690 The concept of information, problem space and ecology are all different ways to say that cognition is 'situated' (e.g. Suchman 1987). Figure 1 acknowledges this by including the ecology as a fundamental component within the system dynamic.

The second source of constraint is the belief system. This reflects the expectations that are held about the ecology and the values associated with those expectations.

695 For example, a goal is an expectation of high value. It is something that we believe will be 'good' for us. This source of constraint is what is conventionally associated with the 'mind'. As noted in the discussion of memory, this is typically conceived as a place to 'store' information. However, we have chosen the term 'belief' to emphasize both the tentative and forward-looking orientation of experience. A belief is an 'expectation' or hypothesis about the future, not a stored 'fact' accumulated from the past. Hypotheses are built from experience, but they are typically not directed to the past, but to the future. Again, as with the ecology, it is best not to associate the belief circle as an attribute of the actor. It is simply a second way to talk about the relationship between actor, stage and play. It is another facet for observing 705 the dynamic flow of experience (i.e. the conversation between mind and matter). In the context of Hutchins' analysis of ship navigation, the belief system might include the knowledge of individual members of the navigation team, as well as the assumptions that are embedded in standard operating procedures and tools of the trade.

710 The term 'belief' is not part of the conventional jargon of cognitive psychology. However, it was at the centre of Dewey's (1991) image of thinking:

The consequences of belief upon other beliefs and upon behavior may be so important, then, that men are forced to consider the grounds or reasons of their belief and its logical consequences. This means reflective thought - thought in its eulogistic and emphatic sense.

Thinking, for the purposes of this inquiry, is defined accordingly as that operation in which present facts suggest other facts (or truths) in such a way as to induce belief in the latter upon the ground or warrant of the former. We do not put beliefs that rest simply on inference on the surest level of assurance. To say 'I think so' implies that I do not as yet know so. The inferential belief may later be confirmed and come to stand as sure, but in itself it always has a certain element of supposition.

(pp. 8-9)

The complementary relationship between the ecology (task environment) and belief system (psychology) in shaping the dynamic of problem-solving is clearly acknowledged by Newell and Simon (1972):

... we shall often distinguish two aspects of the theory of problem solving as (1) demands of the task environment and (2) psychology of the subject. These shorthand expressions should never seduce the reader into thinking that as a psychologist he should be interested only in the psychology of the subject. The two aspects are in fact like figure and ground - although which is which depends on the momentary viewpoint. 
The third source of constraint is the interface. This reflects both the structure associated with the media of perception (e.g. the laws of dynamic perspective associated with optical flow fields) and the structure associated with the mechanisms of perception (e.g. the properties and distribution of rods and cones on the retina). This can include both natural representations (e.g. the view through the windshield) and 'computational tools' (e.g. electronic sensor systems and graphical displays). Hutchins' (1995) discussion of the evolution of maps and other artefacts used in navigation illustrates important aspects of the interface as a constraint on cognition.

With regard to the interface, as a source of constraint, a fundamental question is: 'how well are the consequences and opportunities specified?' The interface is the 'fulcrum' that allows beliefs to be balanced against the ecology. If the consequences and opportunities are well specified, then the cognitive system should evolve toward increased levels of 'fitness' or 'stability'. If the ecology is stable, the dynamic will typically evolve so as to minimize both error and surprise. Our beliefs should tend toward productive relations with the ecology. In a dynamically changing ecology, however, both 'error' and 'surprise' are inevitable, as the belief system struggles to keep pace with those changes. Consistent with the comments about the ecology and belief circles, try not to think of the interface circle as an independent thing, but as simply a third way of talking about the relationships associated with the actor, stage and play - another facet of the dynamic field of experience.

The interactions among the three sources of constraints reflect two competing elemental processes. One process is conventionally referred to as 'control' and the other is conventionally referred to as 'observation' or 'abduction'. In either case, the interface serves the role of a comparator mediating between ecology and belief. In constructing a field like image of the dynamic of experience try to visualize two vector fields that could be superimposed to summarize the significant relations. One vector field would be the field of 'control' and the second field would be the field of 'observation'. In relation to Wheeler and Feynman's comments cited earlier - the fields of control and observation provide a nontrivial alternative for talking about cognitive interactions over space and time.

Dewey (1991) uses different terms, but he describes the dynamic competition between these two fields or 'double movement' vividly.

This double movement to and from a meaning may occur... in a casual, uncritical way, or in a cautious regulated manner. To think means in any case, to bridge the gap in experience, to bind together facts and deeds otherwise isolated.

When pains are made to make each aspect of the movement as accurate as possible, the movement toward building up the idea is known as inductive discovery (induction for short); the movement toward developing, applying, and testing, as deductive proof (deduction, for short).

While induction moves from fragmentary details (or particulars) to a connected view of the situation (universal), deduction begins with the latter and works back again to particulars, connecting them and binding them together. The inductive movement is toward discovery of a binding principle; the deductive toward its testing - confirming, refuting, modifying it on its capacity to interpret isolated details into a unifying experience. So far as we conduct each of these processes in light of the other, we get valid discovery or verified critical thinking. 


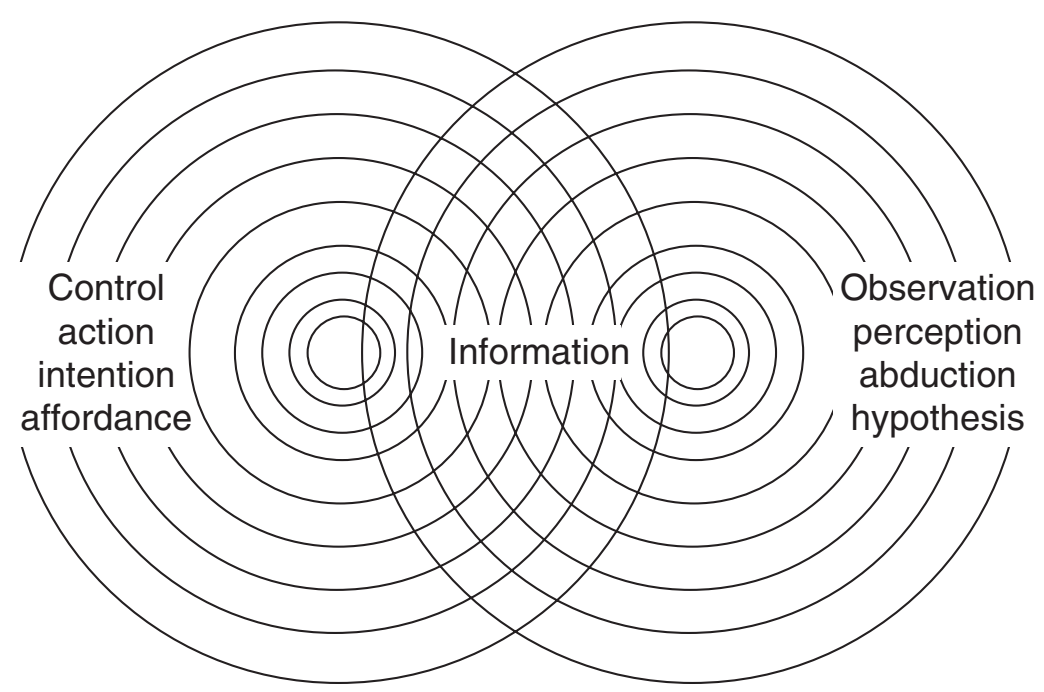

Figure 2. The cognitive dynamic is illustrated as two superimposed fields. One field reflects constraints associated with control, the other reflects constraints associated with observation and the interference pattern reflects the information coupling.

It becomes clear in the context of Dewey's writing that the terms 'induction' and 'deduction' were intended to be understood more broadly than in terms of the formal mathematical/logical concepts. We feel the terms observation (induction) and control (deduction) are better suited. Observation is the process of binding the particulars into expectations that can guide action. Some other words that are commonly used to refer to this aspect of the cognitive dynamic include perception, abduction and hypothesis. Control is the process of acting in ways that 'test' the expectations in terms of the consequences of action. Some other words that are commonly used to refer to this aspect of the cognitive dynamic include action, affordance and intention. Figure 2 illustrates the cognitive dynamic as the superposition of two 'fields', one reflecting the control constraints, another reflecting the observation constraints and the interference pattern reflecting the information coupling. In Hutchins' (1995) terms these fields illustrate the propagation of waves of organization moving back and forth between external (matter) and internal 795 (mind) media.

In the case of control, the interface compares (or mediates between) the intention (arising from beliefs) and the consequences (arising from the ecology). The difference between these is conventionally referred to as the 'error' signal, and this signal is what drives action in a control system. That is, a control system acts to reduce the error (the difference) between the goals (intention) and the output (consequences of the action). Gibson referred to this class of action as performatory action. In a cognitive system the difference between consequence and intention can be resolved either by acting on the ecology to bring the consequences into alignment with the intentions or by retuning or revising the intentions to match the consequences. For example, during landing, the pilot would normally resolve the difference by guiding the aircraft toward the intended touchdown point at the intended speed and descent rate. However, if for some reason (e.g. wind conditions or aircraft conditions) 
this proved difficult or impossible, he may resolve the difference by changing his goal from landing to an alternative course, consistent with procedures for a missed approach. In the wild, it will be rare that there will be a single well-specified goal. The norm will be many competing goals (e.g. economic and organizational pressure to arrive on time vs. safety).

In the case of observation or abduction, the interface compares (or mediates between) the expectations (arising from beliefs) and the consequences (arising from

815 the ecology). The difference between these is 'surprise' and this signal is what drives action in an abductive system (Peirce 1878). Again, there are two ways in which the cognitive system can resolve the surprise. First, the system can change beliefs about the ecology so that new beliefs are more consistent with the observed consequences. This process is typically referred to as 'attunement' or 'learning'. Alternatively, 820 the system can discount, ignore or reinterpret the consequences in a way that they become more consistent with the expectations. For example, the consequences can be attributed to 'noise' or to an exceptional case (e.g. bad luck), rather than to a stable property of the ecology. This type of discounting of information that is inconsistent with beliefs is commonly observed in research on attribution, where people tend 825 to discount information that is inconsistent with early impressions. Similarly, discounting of information is often observed on the path to accidents in humanmachine systems. In the decision literature, this tendency is termed 'confirmation bias' or 'cognitive inertia'. More generally, terms like 'attention capture', 'tunnel vision', 'set effects' and 'fixation' reflect situations where expectations play a dominant role in shaping the experience.

Resolving surprise, as with resolving action, is generally an active process; where hypotheses and beliefs are actively evaluated through interaction with the ecology. For example, tapping the brakes of a new rental car in order to calibrate to the brake dynamics. Gibson used the term 'exploratory action' to refer to actions intended to

835 test expectations. In this system, the ultimate test of a belief is pragmatic, not logical. That is, the test of a belief is its success in guiding action. Beliefs that lead to skilled interactions with the world are confirmed by those interactions, and beliefs that lead to clumsy interactions become suspect. In other words, the test of a belief is not according to the form of the argument as with formal deduction, but rather the test

840 has to do with the stability of progress with regard to intentions or, more drastically, the ultimate test is survival.

In figure 1 the processes of control and observation are not separated as stages in a sequential processing stream. The image is intended to suggest that they are intimately connected to the point where it is impossible to meaningfully distinguish 845 between control and observation; between action and belief; between mind and matter; between stimulus and response, between 'inductive discovery' and 'deductive proof'. However, the circles tend to invite people to visualize a sequences or stages in which they can trace the path of activity along the arrows from one 'object' to the next. The separation between the fields of control and observation are simply convenient ways to talk about the dynamics. There is a single dynamic, but two complementary ways to talk about the dynamic - neither of which captures the full breadth of the interactions. The price paid for the convenience is that each separate field is only a part of the story. A fully coherent picture of cognition requires a superposition of the two fields, as we attempt to illustrate in figure 2 . The complexity 855 that we recognize as intelligent life emerges from this dynamic coupling between control and abduction. It is within this dynamic that meaning is experienced. 
Outside of this dynamic, neither the objects in an ecology nor the objects in a mind have full meaning or make complete sense. Thus, meaning is neither of mind nor of matter. Sense is made or meaning is constructed in the dynamics of this coupling between control and abduction. The dynamic determines what matters!

\section{The nature of events}

Of all the obstacles to a thoroughly penetrating account of existence, none looms up more dismayingly than 'time'. Explain time? Not without explaining existence. Explain existence? Not without explaining time. To uncover the deep and hidden connection between time and existence, to close on itself our quartet of questions, is a task for the future.

(Wheeler 1994, p. 191)

... space and time are orders of things and not things.

(G.W. Leibnitz 1708)

... time and space are modes by which we think and not conditions in which we live.

(Einstein 1963)

The diagram in figure 1 is intended to illustrate the coupling of multiple sources of constraint. However, with this type of diagram there remains a strong temptation to think about the dynamic as a sequence of activities - an intention leads to an action; which in turns leads to a consequence; which in turn leads to an error signal; which in turn leads to another action, etc. Thus, the continuous dynamic of cognition is conventionally parsed into a discrete sequence of activities - like dominoes, one causing the next collision and then the next, or like frames in a movie. This temptation has a lot to do with our image of time as a sequence of discrete moments with an absolute present, past and future. This idea is implicit even in relativistic models of space-time as reflected in the light cones illustrated in figure 3.

With the image of time shown in figure 3, life unfolds as a sequence of moments. The state at any moment is 'caused' by events in the past, and the future remains a set of unrealized potentials. In physical systems both the frame of possible causes and the frame of possible futures are bounded by the physical limits of the system (e.g. by the speed of light). The same image might be applied to a cognitive system. In this case, the boundaries of plausible 'causes' and 'feasible' goals might reflect either physical limits (e.g. how fast an animal or vehicle can move) or cognitive limits (beliefs or knowledge). For example, a common complaint about automation is that features of operation may be hidden (e.g. advanced functions for building templates in a word processing program). That is, there may be paths to a person's goal using the automation that are never considered because they are obscured in the design of the interface. These paths are effectively outside the space of possibilities

895 because they are invisible to the person using the automation. Similarly, a person's interpretation of an historical episode can be limited by (or biased) by their knowledge or beliefs. This may limit what can be 'learned' from the past - that is, how the past can shape (or cause) the cognitive state in the present. In essence, the plausibility constraints lead to the hindsight bias.

900 How knowledge and beliefs can bound the space of possibilities for a cognitive system is an important generalization from relativistic images of time to our image of 


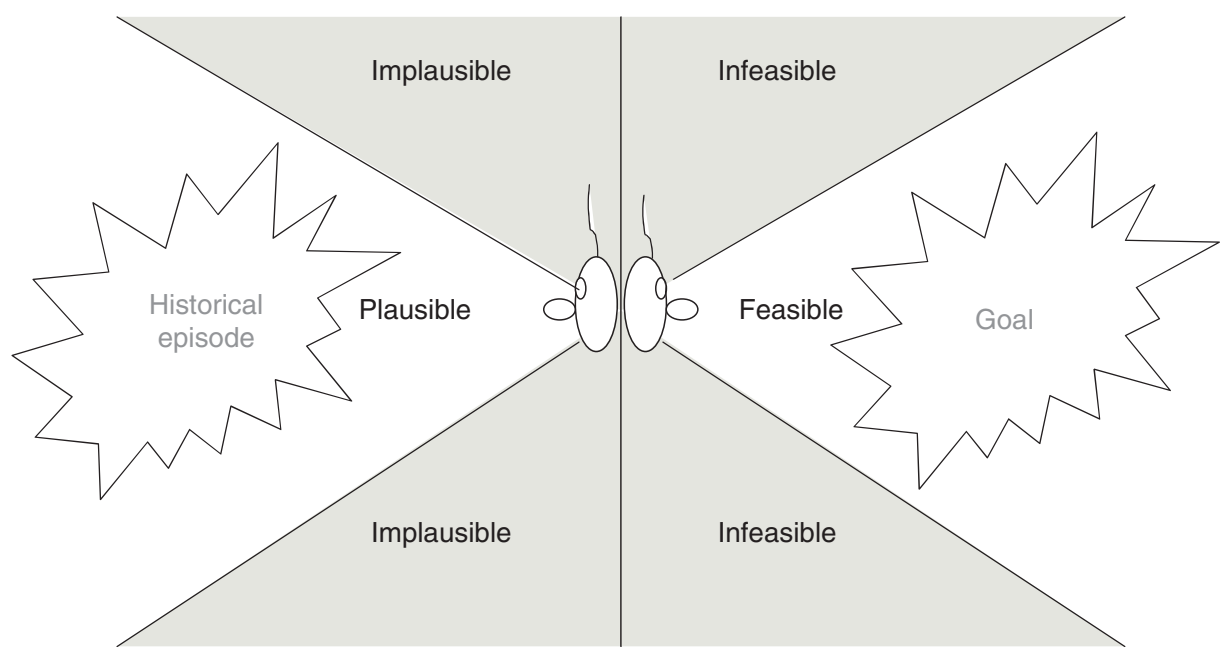

Figure 3. A conventional image of time where the cognitive system lives in an absolute present between the absolute past and absolute future. Time unfolds as a linear sequence of moments like frames in a movie. The shaded regions are outside the field of possible experiences (impossible states). The white cones reflect the field of possible experiences.

the cognitive dynamic. However, even with these constraints, the image in figure 3 still invites a snapshot image of time that unfolds from frame to frame, with causes to future frames residing in past frames. In this image, there is only the present moment. The past is carried into this moment only to the extent that it is stored in memory and then brought to mind or remembered. The future exists in the moment only to the extent that it is reflected in 'plans' that the person is currently reflecting on. Neither the past nor future exists - they are mere shadows carried in the mind of the cognitive system. In this context, 'teleology' becomes a problem because it goes against the direction of flow.

Figure 4 shows an alternative image for an event. In this image, the relationship between the current state of the cognitive system and the goal is illustrated. The constraints expanding forward from the historical episode reflect the possibilities that are deemed 'feasible' based on experience. The constraints expanding back 915 from the goal reflect the possibilities that are deemed 'plausible' paths to the goal. Again, both sets of boundaries can reflect both physical and cognitive constraints. It is in this extended space between past experience and intended goal that the dynamic illustrated in figure 1 is played out. Shaw and Kinsella-Shaw (1988) called this the event space. It reflects the conjoint relation that is essential to any control/ observer dynamic. It reflects a circular causality in which neither perception nor action is a 'cause' or 'stimulus' with regard to the other. Rather, perception and action mutually and continually constrain each other. In the parsing of action in figure 4 , relative to figure 3 , the emphasis is on the future as shaped by the feasibility of action relative to the current state and the plausibility of paths toward an intended goal. Thus, the event space is a space of what might happen, as simultaneously constrained by capability and intention. The space reflects both past experience as it contributes to capability and future goals as they are selected from among the diverse possibilities. It is not a space of what has already happened. We believe that this is 


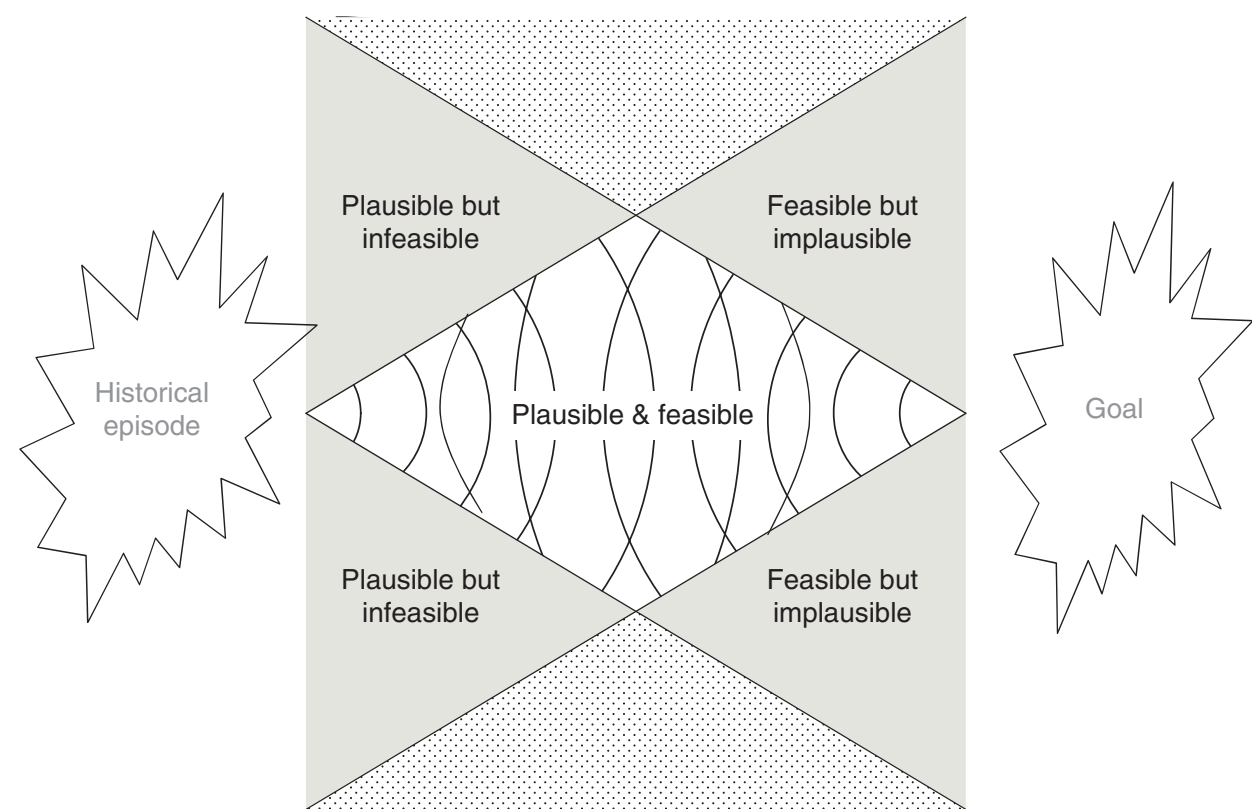

Figure 4. An event space that reflects the conjoint, mutually constraining relations between experience and intention.

where meaning lives. The past is the domain of dead truths - the future is where meaning comes alive.

Long ago James (1892) argued that the concept of an absolute present was 'specious' (i.e. false or illusory):

Let anyone try, I will not say to arrest, but to notice or attend to, the present moment of time. One of the most baffling experiences occurs. Where is it, this present? It has melted in our grasp, fled ere we could touch it, gone in the instant of becoming... It is, in fact, an altogether ideal abstraction, not only never realized in sense, but probably never even conceived of by those unaccustomed to philosophic meditation. Reflection leads us to the conclusion that it must exist, but that it does exist can never be a fact of our immediate experience. The only fact of our immediate experience is what has been well called 'the specious' present, a sort of saddle-back of time with a certain length of its own, on which we sit perched, and from which we look in two directions into time. The unit of composition of our perception of time is a duration, with a bow and a stern, as it were - a reward - and a forward-looking end. It is only as parts of this duration-block that the relation of succession of one end to the other is perceived. We do not first feel one end and then feel the other after it, and from the perception of the succession infer an interval of time between, but we seem to feel the interval of time as a whole, with its two ends embedded in it. The experience is from the outset a synthetic datum, not a simple one; and to sensible perception its elements are inseparable, although attention looking back may easily decompose the experience, and distinguish its beginning from

(pp. 280-281)

In figure 4, the concept of an absolute present is replaced by the concept of an event that is extended over time. In this framework the absolute present is both 
'specious' (i.e. fictional) and 'spacious' (i.e. extended, not instantaneous). Just as the concept of 'chunk' is needed to understand how objects (e.g. pieces on a chessboard) can be parsed into meaningful units, the concept of event is needed to understand how to parse sequences into meaningful units. To understand the dynamics of cognition our concept of the layout of the chessboard in space and the sequence of moves in time must be partitioned to reflect intrinsic properties of the dynamic (units of meaning), not extrinsic properties that were chosen in the context of a Newtonian programme where space and time were considered to exist independently from the phenomena that they indexed and from each other. The circular coupling illustrated in figure 1 demands that we abandon our conventional notions of both space and time to understand how the sharp edges of experience and intention simultaneously shape the path of cognition.

The idea of feasibility reflects a projection-forward from the sharp edge of experience. This is similar to what Piaget called assimilation, in which the future is framed in terms of skills that have worked in similar contexts. In figure 4, the goal falls within the feasible space. This may not always be the case. In some cases there

970 may be no feasible path to the goal or the links between feasible paths and plausible paths to the goal will not be clear. Figure 5 illustrates the situation where the path to the goal or the hidden dangers within the event space may not be clear when living down in the trees. Of course, these paths may be clearer with the perspective of hindsight.

975 When the goal falls well within the feasible space, the dynamic of cognition will be essentially one of control - directing action along feasible paths using skills developed through experience. However, when the goal falls outside of the feasible space or when the paths to the goal are not obvious, then the cognitive dynamic will be dominated by abductive problem-solving, as the system must explore hypotheses

980 in order to discover a feasible path. In this case, an accommodation process may be required to adapt to new demands on performance. In most cases, the path forward will reflect combinations of assimilation and accommodation; of control and abduction; of performatory and exploratory actions, of inductive discovery and deductive proof.

985 In thinking about events as reflected in figures 4 and 5, attention naturally shifts from points or moments to paths (or world lines) that connect experience with intentions. This is most clear in figure 5, where it is natural to search for the paths in the maze that link the start with the goal. Physicists refer to the paths through Minkowski space as 'world lines'. In the event space, the world lines that become 990 most interesting with regard to cognitive dynamics are those lines that connect the sharp edge of experience at one corner with the intention on the other corner. These are the threads that give meaning to action. Of the possible paths that link the corners of the event space it is natural to compare them in terms of their 'optimality', where optimality will generally be an integral property of the path - the 'costs'

995 and 'benefits' that accrue as the path is travelled. The optimal path is one that maximizes benefits while minimizing costs. In economic approaches to rationality, as Newell and Simon (1972) observe, the paths can be ranked with little thought to 'psychology':

It would be perfectly possible for the psychologist to follow the route of the economist: to construct a theory of concept formation that depended on no characteristic of the subject other than his being motivated to perform well. It would be a theory of how perfectly 


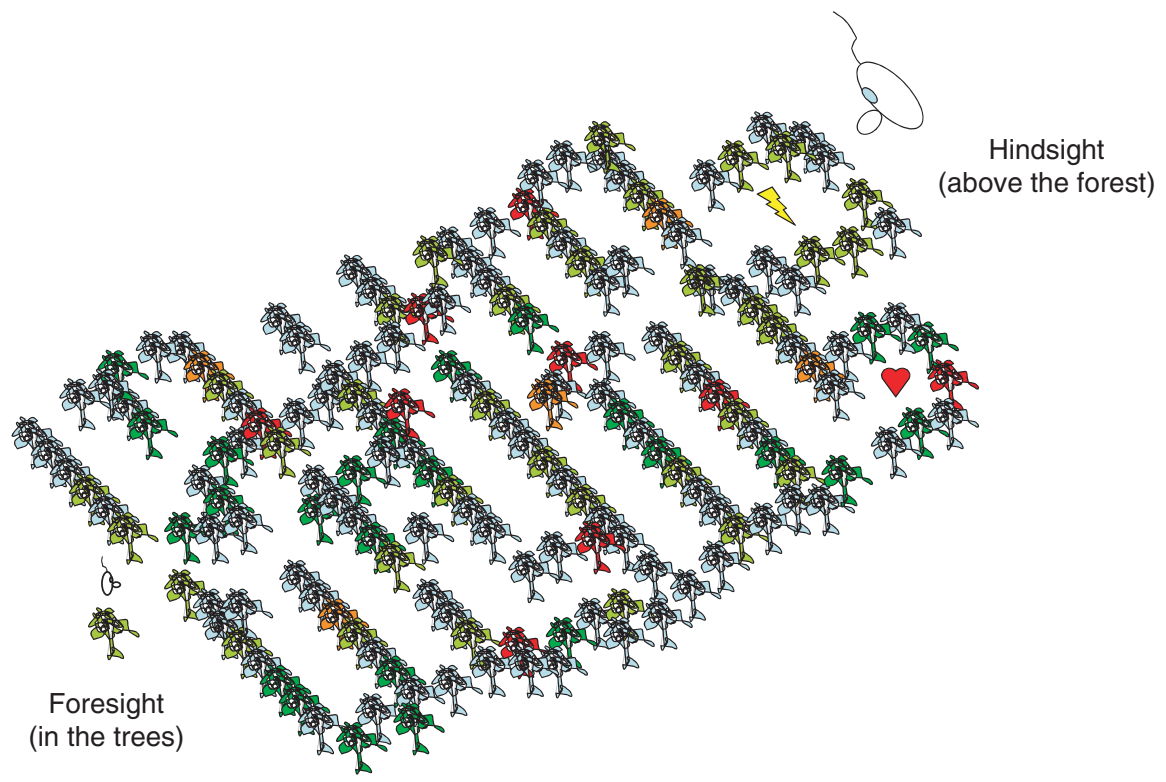

Figure 5. The paths through the event space to the goal (heart) or to hidden dangers (the lightning bolt) may not be well specified. Thus, movement across the event space will require a combination of abduction and control.

rational man would behave in that task environment - hence, not a psychological theory but a theory of the structure of the task environment.

However, Newell and Simon (1972) continue on to observe that things become interesting when empirical observations reveal that the paths or world lines that people actually travel are not those deemed optimal by the economic models. They suggest that the explanation for the difference 'must lie inside the subject; in limits of his ability to determine what the optimal behavior is' (p. 55). This is probably a fairly accurate assessment for the well-defined problems that Newell and Simon tended to study (e.g. cryptoarithmetic, chess, etc.). In fact, 'well-defined' simply means that we have well-validated economic models of the task environment (assuming that the experimental participants choose to play our game and ignoring the demand characteristics of the experimental context). However, when studying 1015 human behaviour in more complex, open environments, such as in most real work domains, we can never be sure whether the deviations from expectations based on our 'economical' models of rationality are due to limits inside the humans or to the limits of our economical models. In other words, researchers studying cognition in the wild can never share the bench cognitive scientists' confidence that the path he/she (the scientist) thinks is the optimal path through the event space is truly the optimal path.

When studying cognition in the wild, the researcher must simultaneously construct a model of the ecology (task environment) and the belief system (psychology). In many cases, people studying cognition in the wild discover that behaviours that at first appeared to them to be 'irrational' are later discovered to be 
perfectly reasonable as they get a deeper understanding of the work domain constraints. Often, the best guide to the economically optimal path will be the behaviour of domain experts. But of course, this guess is confounded by the beliefs of the experts. In complex work domains, one must be sceptical about whether even the experts have a complete model of the task constraints. This is further complicated by the fact that the work domains themselves are changing continuously as a result of innovations of the people within them, as reflected by the dynamic coupling illustrated in figure 1. Because of the evolving dynamic of natural work domains, an asymptotic approach to understanding the deep structure of the problem space is probably the best that we can hope for.

Of course, while the space illustrated in figures 4 and 5 are essentially twodimensional due to the constraints of paper representation, the event space of cognition is n-dimensional, with multiple dimensions needed to characterize the state of experience on the left point of the event diamond and multiple intentions or goals 1040 competing to constrain the dynamic from the right point of the diamond. Figure 4 is only a cartoon to stimulate the imagination to consider unconventional images of time. One of the key questions for work domain analysis (e.g. Vicente 1999) is to map out the multiple layers of constraint within the event space. In most cases, it will not be simple to visualize these constraints within a single representation or within a 1045 single level of abstraction. This is one of the important lessons of Rasmussen's (1986) Abstraction Hierarchy. It makes it clear that each level provides a different perspective on the event space. Each perspective reveals some aspects of the event space and hides other aspects. Representations at each level provide unique insights into the event space. The more levels/representations considered, the deeper will be

1050 our understanding of this space.

\section{Closing or escaping the circle}

The point is that the universe is a grand synthesis, putting itself together all the time as a whole. Its history is not a history as we usually conceive history. It is not one thing 1055 happening after another after another. It is a totality in which what happens 'now' gives reality to what happened 'then', perhaps even determines what happened then.

(Wheeler 1998, p. 338)

To summarize, the major premise of this reverie is that the phenomenon of cognition as it unfolds in the day-to-day activities of work and play cannot be 1060 understood using conventional notions of causality and time. The conventional notions lead to theories of human error with little connection to human ability or skill. The conventional notions lead to theories of memory, with little connection to the phenomena of learning and skill development. The conventional notions lead to a static image of mental life that is hopelessly disconnected from the dynamic world of what matters.

A first step toward breaking free of the conventional notions is to replace the term cause with the term constraint. In a circular dynamic, as illustrated in figures 1 and 2 with the associated image of event illustrated in figures 4 and 5, there is no clear basis to differentiate cause from effect or stimulus from response. The ecology, information and beliefs simultaneously shape and are shaped by each other. 
The world lines of cognition emerge from this dynamic coupling of multiple sources of constraint - none of which can be isolated as a cause of the other.

When considering the coupling of mutual constraints, the classical notion of time as unfolding one moment after another loses its value. Unlike causes, constraints do not exist in time, but over time. They are not sequential, like dominoes falling in a line or frames in a movie. Rather, constraints are locked, like partners in a dance. The steps in the dance may be sequential, but one step does not cause the next. The conceptual objects for a cognitive science are not these steps, but the partners (ecology, information and beliefs) who are continually contributing to the dance - sometimes leading and sometimes following the others.

We use the term 'conceptual objects' to emphasize that the partitioning of the dynamic in figure 1 reflects what we believe to be a useful chunking of the phenomenon of cognition for the purposes of science and design. However, the dynamic of cognition is reflected in the arrows not the circles. That is, a dynamic process is best conceived of as a field, as illustrated in figure 2 - not a collection of particles. The circles simply reflect convenient landmarks so that the scientist and designer can orient within this dynamic field and carry forward the insights from previous paradigms. Without landmarks such as these, there is a danger that both the scientist and designer will be caught in an endless circle - destined to repeat the same mistakes

1090 and arguments over and over again without progress. The challenge is not to replace the old buckets of water with newly labelled buckets, but to get past the buckets of water to engage the stream of life that is bubbling all around us.

Continuing the theme of the circle, we think it is interesting to reflect back on the work of early psychologists such as James, Peirce and Dewey. There are many 1095 interesting similarities in the dynamics described by these early functionalists and the dynamics being 'discovered' by current researchers who are exploring cognition in the wild; by physicists exploring at the smallest and largest scales of nature; and by recent interest in the language of dynamical systems for describing self-organization at ecological scales of nature. It seems that this dynamic was lost to psychology in the second half of the 20th century. Perhaps this is because the formalisms (both theoretical and methodological) of the behaviourist and informationprocessing paradigms occluded this dynamic. The communication channel and computer metaphor invited a parsing of cognition into a sequence of distinct stages a sequence of dominos, one bumping into the next in discrete moments of time.

1105 Missing from this dynamic is the intimate coupling of observation and control, each simultaneously shaping and being shaped by the other within a unified event extended over time. Perhaps the language of dynamical systems and the associated images of self-organizing systems will provide a context for us to retrace the circle and rediscover and revitalize some of the insights of the early functionalists. Perhaps

1110 it would be valuable to reconsider some of the metaphysical implications of pragmatism and radical empiricism for our image of experience and cognition. Perhaps this will help us to solve the surprise version of the Twenty Questions game and to build a theoretical framework that will provide guidance for the design of cognitive systems that are more reliable.

1115 In sum, at present there seems to be a huge gap, which Percy (1991) characterized as 'the San Andreas Fault in the modern mind'. He writes:

I refer to this gap in scientific knowledge as an incoherence, from the Latin in-cohaerere, a not sticking together. By this word I mean that we are not talking an ordinary area of 
ignorance which is being steadily eroded by advancing knowledge - like the tremendous advances in cosmology or in the physics of subatomic particles. No, this gap is incoherent and intractable, at least from the present posture of natural science. That is to say, no amount of effort by 'brain' scientists and 'mind' scientists can even narrow the gap. It is not like tunneling under a river from both sides and meeting in the middle. It is more like ships passing in the night.

(pp. 275-276)

In a similar vein, Dreyfus (1994) observes:

Looking back over the past ten years of AI research we might say that the basic point which has emerged is that since intelligence must be situated it cannot be separated from the rest of human life. The persistent denial of this seemingly obvious point cannot,

1130 however, be laid at the door of AI. It starts with Plato's separation of the intellect or rational soul from the body with its skills, emotions, and appetites. Aristotle continued this unlikely dichotomy when he separated the theoretical from the practical, and defined man as a rational animal - as if one could separate man's rationality from his animal needs and desires. If one thinks of the importance of the sensory-motor skills in the development 1135 of our ability to recognize and cope with objects, or the role of needs and desires in structuring all social situations, or finally of the whole cultural background of human selfinterpretation involved in our simply knowing how to pick out and use chairs, the idea that we can simply ignore this know-how while formalizing intellectual understanding as a complex system of facts and rules is highly implausible. However, incredible, this dubious

1140 dichotomy now pervades our thinking about everything including computers.

The central question of this article is whether the image of two interacting fields, one reflecting constraints on control, the other reflecting constraints on observation, will provide a more meaningful way to talk about the dynamics of cognition.

1145 Can the lessons of quantum mechanics help us to bridge the huge fault between the classical constructs of mind (the rational) and matter (the physical)? Can the 'duality' (or complementary nature) of control and observation help us to get past the 'dichotomy' (or distinctive nature) of mind and matter? Will it be easier to pull together the images of control and observation into a coherent picture or tractable

1150 model of cognition? And by doing so, will this lead to a more symbiotic relation between cognitive science and cognitive engineering?

Hutchins' (1995) suggests that the first step to answering these questions is a 'cognitive ethnography' to describe cognition in the wild. While we do not doubt the importance of this step, we believe that perspicuity will depend on the ontological

1155 frame that we use to make sense of these observations. We suggested that the first step to a cognitive science of 'what matters' is a single ontology that spans both mind and matter. There can be no coherent cognitive systems engineering if our theories of cognitive systems are framed in one ontology and our theories of engineered systems are framed in another. The goal of this paper was to suggest an ontology for 1160 cognitive systems engineering.

\section{References}

Adams, M.J., Tenney, Y.J. and Pew, R.W., 1995, Situation awareness and the cognitive management of complex systems. Human Factors, 37, pp. 85-104. 
CArroll, J.S., 1978, The effect of imagining an event on expectations for the event: an interpretation in terms of the availability heuristic. Journal of Experimental Social Psychology, 14, pp. 88-96.

6

Carroll, L., 1871, Through the Looking Glass (London: D).

Dewey, J., 1991, How We Think (Amherst, NY: Prometheus Books). (originally published in 1910).

1170 Dominguez, C.O., 1995, First, do no harm: Expertise and metacognition in laparoscopic surgery. Unpublished Doctoral Dissertation. Wright State University, Dayton, OH.

Dreyfus, H.L., 1994, What Computers Still Can't Do: A Critique of Artificial Reason (Cambridge, MA: The MIT Press).

Einstein, A., 1963, Albert Einstein, Theoretical Physicist (New York: D).

1175 Feynman, R., Leighton, R.B. and Sands, M., 1963, The Feynman Lectures on Physics (Reading, MA: Addison-Wesley Publishing Co.).

Fischoff, B., 1975, Hindsight $\neq$ Foresight: The effect of outcome knowledge on judgment under uncertainty. Journal of Experimental Psychology: Human Perception and Performance, 1(3), pp. 199-288.

1180 Fischoff, B., 1982, For those condemned to study the past: Heuristics and biases in hindsight. In Judgments Under Uncertainty: Heuristics and Biases, D. Kahneman, P. Slovic and A. Tversky (Eds.), pp. 335-351 (Cambridge: Cambridge University Press).

Forster, E.M., 1972, Aspects of the Novel (San Diego, CA: Harcourt).

Gibson, J.J., 1979, The Ecological Approach to Visual Perception (Boston, MA: Houghton-Mifflin). 1185 Gibson, J.J. and Crooks, L., 1938, A theoretical field-analysis of automobile-driving. American Journal of Psychology, 51, 453-471. Reprinted in E. Reed and R. Jones (Eds.) (1982). Reasons for Realism (Hillsdale, NJ: Erlbaum).

Hawkins, S. and Hastie, R., 1990, Hindsight: Biased judgments of past events after the outcomes are known. Psychological Bulletin, 103, pp. 311-327.

1190 Hutchins, E., 1995, Cognition in the Wild (Cambridge, MA: The MIT Press).

JaGacinski, R.J. and Flach, J.M., 2003, Control Theory for Humans (Mahwah, NJ: Erlbaum).

James, W., 1890, The Principles of Psychology, Vol. 1 (New York: Henry Holt \& Co.).

James, W., 1892, Psychology (New York: Henry Holt \& Co.). (1909).

1195 Jones, E.E. and Nisbett, R.E., 1971, The Actor and the Observer: Divergent Perceptions of the Causes of Behavior (Morristown, NJ: General Learning Press).

Juarrero, A., 1999, Dynamics in Action (Cambridge, MA: The MIT Press).

Koehler, D.J., 1991, Explanation, imagination, and confidence in judgment. Psychological Bulletin, 110, pp. 499-519. G.M. Duncan (Ed.) (New Haven, CT: D). (1908).

Loftus, E.F., 1975, Leading questions and the eye-witness report. Cognitive Psychology, 7, pp. $560-572$.

Mach, E., 1905, Knowledge and Error, English ed. (Dordrecht, The Netherlands: Reidel). 1976.

Medin, D.L. and Ross, B.H., 1992, Cognitive Psychology (Fort Worth, TX: Harcourt Brace Jovanovich College Publishers).

Menand, L., (Ed.), 1997, Pragmatism (New York: Vintage Books).

Menand, L., 2001, The Metaphysical Club (New York: Farrar: Straus and Giroux).

Miller, G.A., Galanter, E. and Pribram, K.H., 1960, Plans and the Structure of Behavior (New York: Henry Holt and Company).

1210 Neisser, U., 1976, Cognition and Reality (San Francisco: W.H. Freeman).

Newell, A., 1973, You can't play twenty questions with nature and win. In Visual Information Processing, W.G. Chase (Ed.), pp. 283-308 (New York: Academic Press).

Newell, A. and Simon, H.A., 1972, Human Problem Solving (Englewood Cliffs, NJ: Prentice-Hall, Inc.).

1215 Peirce, C.S., (1878), Deduction, induction, and hypothesis. In The Writings of Charles S. Peirce: A Chronological Edition. Compiled by the editors of the Peirce edition project. Vol. 30. (Bloomington, IN: Indiana University Press). (1982).

Percy, W., 1991, The fateful rift: The San Andreas Fault in the modern mind. Signposts in a Strange Land (New York: Picador).

1220 Perrow, C., 1984, Normal Accidents (New York: Basic Books, Inc.).

Powers, W., 1973, Behavior: The Control of Perception (New York: Aldine de Gruyter). 
Powers, W., 1998, Making Sense of Behavior: The Meaning of Control (New Canaan, CT: Benchmark Publications Inc.).

Rasmussen, J., 1986, Information Processing and Human-Machine Interaction (New York: North-Holland).

Rasmussen, J. and Svedung, I., 2000, Proactive Risk Management in a Dynamic Society (Karlstad, Sweden: Swedish Rescue Services Agency).

Reason, J.A., 1990, Human Error (Cambridge, UK: Cambridge University Press).

Roese, N.J. and Olson, J.M., 1996, Counterfactuals, causal attributions, and the hindsight bias: A conceptual integration. Journal of Experimental Social Psychology, 32, pp. 197-277.

Ross, L., 1977, The intuitive psychologist and his shortcomings: Distortions in the attribution process. In Advances in Experimental Social Psychology, Vol. 10, L. Berkowitz (Ed.), (New York: Academic Press).

Shannon, C.E. and Weaver, W., 1949, The Mathematical Theory of Communication (Urbana, IL: University of Illinois Press).

Shaw, R. and Kinsella-Shaw, J., 1988, Ecological mechanics: A physical geometry of intentional constraints. In Self-organization in Biological Workspaces, P. Kugler (Ed.), (Berlin: SpringerVerlag).

Simon, H.A., 1981, The Sciences of the Artificial, 2nd ed. (Cambridge, MA: MIT Press).

1240 Smith, K. and Hancock, P.A., 1995, Situation awareness is adaptive, externally directed consciousness. Human Factors, 37, pp. 137-148.

Snook, S.A., 2000, Friendly Fire (Princeton, NJ: Princeton University Press).

Suchman, L., 1987, Plans and Situated Actions: The Problem of Human-Machine Communication (Cambridge: Cambridge University Press).

1245 Vicente, K.J., 1999, Cognitive Work Analysis (Mahwah, NJ: Erlbaum).

WeICK, K., 1995, Sensemaking in Organizations (Thousand Oaks, CA: Sage Publications).

Wheeler, J.A., 1980, Frontiers of time. In Problems in the Foundations of Physics, G. Toraldi di Francia (Ed.), (Amsterdam: North-Holland).

Wheeler, J.A., 1994, At Home in the Universe (New York: AIP Press).

1250 Wheeler, J.A., 1998, Geons, Black Holes, and Quantum Foam (New York: W.W. Norton \& Company).

Woods, D.D., Johannsen, L.J., Cook, R.I. and Sarter, N.B., 1991, Behind Human Error: Cognitive Systems, Computers, and Hindsight (Alexandria, VA: Defense Technical Information Center).

\section{Biographies}

1255 John Flach is Professor and Chair of Psychology at Wright State University, Dayton, $\mathrm{OH}$. Seeking solutions to his ineptitude at sports, music and with technology, John has spent over 25 years studying and teaching topics related to the performance of human-machine systems. This has included research related to the domains of aviation, medicine and highway safety. Most recently, he participated on the Human

1260 Systems Assessment team for evaluating advanced design concepts for future Combat Air Operations Centers (JEFX'04 and'06). Key publications include the book Control Theory for Humans (with R. Jagacinski) and two edited volumes on ecological approaches to human-machine systems (with Hancock, Caird and Vicente). Despite extensive publications, John has failed to achieve his initial 1265 goals. He remains a clumsy athlete and musician and he still struggles with even the simplest technologies.

Sidney Dekker is Professor of Human Factors and Flight Safety, and Founding Director of Science and Research at Lund University, School of Aviation, Sweden. With two Dutch Master's degrees in Psychology, he gained his PhD in Cognitive Systems Engineering from The Ohio State University, USA. He has worked in 
Australia, New Zealand, the Netherlands and England and has been a Senior Fellow at Nanyang Technological University in Singapore. His research interests include system safety, human error, reactions to failure and organizational resilience. He flies as instructor pilot at Lund University School of Aviation. His most recent books are

1275 Ten Questions About Human Error: A New View of Human Factors and System Safety (2005) and The Field Guide to Understanding Human Error (2006).

Pieter Jan Stappers received the MSc in experimental physics in 1984. Then he made the switch to Industrial Design Engineering at TU Delft and followed a research path that led from human perception, spatial imagery, virtual reality ( $\mathrm{PhD}$ in 1992) to design tools and participatory design techniques. His current activities as full professor of design techniques (as of 2002) encompass coordinating Delft's new Master program of Design for Interaction, being informal director of ID-StudioLab, and heading the research subprogram on tools and techniques for the conceptual phase of design. Key elements in his work are 'research through design', 'experiential prototypes' and context mapping, which can be found on his webpage (http:// studiolab.io.tudelft.nl/stappers/). 